\title{
Increased daily activity in cystic fibrosis: time to break out the prescription pad?
}

\author{
Dominic A. Fitzgerald
}

Affiliations: Dept of Respiratory Medicine, The Children's Hospital at Westmead, Sydney, and Discipline of Paediatrics and Child Health, Sydney Medical School, University of Sydney, Sydney, Australia.

Correspondence: D.A. Fitzgerald, Dept of Respiratory Medicine, The Children's Hospital at Westmead, Locked Bag 4001, Westmead, Sydney, New South Wales, 2145 Australia. E-mail: dominic.fitzgeraldahealth.nsw.gov.au

Increased physical activity from the start, now surely that can't be too hard to prescribe? http://ow.ly/qMgY1

\begin{abstract}
After more than 30 years, the medical world has come to accept the virtues of newborn screening for the diagnosis of cystic fibrosis (CF). Evidence from Europe, Australia and the USA has demonstrated benefits in terms of nutrition, lung function and survival into adulthood [1,2]. Similarly, evidence exists that children who present with meconium ileus do worse from the respiratory viewpoint than those diagnosed on newborn screening, supporting the argument that genotypic-phenotypic differences remain incompletely understood [3]. Such observations have been further reinforced by work from the AREST CF (Australian Respiratory Early Surveillance Team for Cystic Fibrosis) group from Australia, demonstrating the early onset of structural lung disease $[4,5]$, and the London CF consortium [6] and American researchers [7] who have recently shown the benefits on lung function in young children with CF diagnosed by newborn screening compared with those diagnosed at a later stage when symptomatic. The complementary nature of structural and functional lung assessment in providing a broader assessment of the status of young people with CF [8] highlights additional concerns for clinicians managing the routine care of "well" infants and young children with CF. The accumulated evidence argues that the lungs of young children with CF are vulnerable from birth and, whilst newborn screening is clearly beneficial, it is routine practice in many centres to place an emphasis on airway clearance [9] from the start with a view to improving short-term and long-term outcomes. However, this is not necessarily the case, according to a recent Cochrane Review which found evidence to support the role of airway clearance techniques in increasing mucus transport with shortterm benefits only [10].
\end{abstract}

Whilst proof-of-concept medications such as Ivacaftor are life changing for a 5\% subset of CF patients [11], the reality for the remaining $95 \%$ of people living with CF is that beyond the use of standard treatments, including dornase alfa, mannitol, hypertonic saline, daily airway clearance therapy, antibiotics and pancreatic enzyme replacement therapy, further therapies in the near future will not offer a "magic bullet". Realistically, it is by optimising routine care that we, as clinicians, will bring incremental benefits in terms of quality of life and longevity [12]. Perhaps the beneficial effects of doing the basic things better can be overlooked in anticipation of successful and effective gene therapy which remains elusive, 25 years after the discovery of the first and most ubiquitous CF gene p.delF508?

Much to the relief of clinicians who are "true believers" in the sustained benefits of airway clearance techniques, some evidence has emerged in an article by SCHNEIDERMAN et al. [13], in this issue of the European Respiratory Journal, on the longitudinal beneficial aspects of increased habitual activity in relation to lung function. Supporting the concept that increased activity improves mucociliary clearance through improved ion channel function with improved hydration of airway mucus [14], SCHNEIDERMAN et al. [13] have demonstrated the value of increasing regular activity in terms of slowing the rate of decline in forced

Received: Oct 102013 | Accepted: Oct 212013

Conflict of interest: None declared.

Copyright @ERS 2014 
expiratory volume in $1 \mathrm{~s}$ (FEV1) \% predicted during the adolescent years. At the start of the study, the subjects from two Canadian centres were early adolescents (mean age 12 years) with mild lung disease (mean FEV1 85\% pred) and were followed for a median of 5.2 years (range 1-9 years). They were diagnosed clinically. Habitual activity increased with age, but more importantly, those with higher activity levels at baseline fared better. When divided into those above and below the mean rate of change in habitual activity, a modest increase in daily habitual activity of as little as 17 min slowed the decline in FEV1 \% pred by $0.58 \%$ per year, or about one third to a half of the annualised rate of decline identified in longitudinal studies of 1-2\% per year.

The aerobic capacity of children has been shown to be a useful predictor of outcomes such as lung function and potentially may be helpful in predicting survival [15-17]. In the current study, SCHNEIDERMAN et al. [13] found the peak oxygen consumption $\left(V^{\prime} \mathrm{O}_{2}\right.$ peak $)$ and peak work rate declined longitudinally commensurate with the rate of decline in FEV1 \% pred, extending similar observations made after a 2 year follow-up by KLIJN et al. [18] who studied children with CF from Holland.

Maximal exercise testing, a dynamic test as opposed to static spirometry, provides a useful method for assessing and tracking respiratory limitation [19] and maximal exercise capacity $V^{\prime} \mathrm{O}_{2}$ peak. However, it has limitations as it requires subjects to be of a certain height and be cooperative with the testing regime. To circumvent this, investigators have used field tests of sub-maximal exercise tests to estimate peak exercise capacity with shuttle tests [20]. Nonetheless, other investigators have questioned whether even a maximal exercise test in paediatric subjects with $\mathrm{CF}$, using traditional criteria to verify maximal efforts, is as good as a subsequent exhaustive supramaximal exercise test [21,22]. Other investigators have used body size [23] and diffusing capacity of the lung for carbon monoxide [24] to predict $V^{\prime} \mathrm{O}_{2}$ peak, highlighting that estimated $V^{\prime} \mathrm{O}_{2}$ peak may be useful across the spectrum school-aged children for longitudinal evaluation if there is reasonable concordance between methods of calculating the figure. A simple estimate of $V^{\prime} \mathrm{O}_{2}$ peak, matched with questionnaire derived habitual activity data, as carried out by SCHNEIDERMAN et al. [13], would offer a potentially useful and simple test that could be applied broadly across countries with limited resources for exercise testing in order to obtain potentially useful international data on outcomes.

Lest one get too carried away with the simplicity of advocating the benefits of increased habitual activity from the cradle to the grave, it would be remiss not to consider "the elephant in the room" when considering any added impost on the "burden" of care for children and families living with chronic illness. Adherence to daily therapies is challenging for some families who tend to be selective and inconsistent about the therapies that they embrace, despite a desire to comfort and reassure the most empathetic of clinicians [12]. This begins in childhood and becomes entrenched by adolescence [25, 26]. Convincing an adolescent, with or without $\mathrm{CF}$, to undertake additional responsibilities requires patience and perseverance in establishing the importance of undertaking these additional responsibilities. In fact, it involves art as well as science in selling the increased treatment options. In this setting, a touch of vaudeville may prove an eighth alternative to evidence based medicine [27]! Regardless of how the message is delivered, it must be delivered and reinforced regularly in an analogous manner to which we emphasise the need for pancreatic insufficient patients to embrace the "High fat high energy" CF diet and take their enzymes from the start to maintain their growth and general health [28].

For paediatricians, the virtue of increased habitual activity should not be restricted to young people with $\mathrm{CF}$, but should form part of a generic prescription for all children in the broader population as society attempts to combat the tsunami of obesity that confronts us today [29]. From a societal viewpoint, increased habitual activity is inexpensive and easy to implement without the challenges of formalised exercise training programmes. Therefore, as physicians advocating for the care of people living with CF, we must encourage optimal management strategies in tailoring care in a time of "personalised medicine" for our CF patients. Optimal care begins with achievable care. Ideally, the message must be simple, practical, consistent and inexpensive for our healthcare systems. Increased physical activity from the start, now surely that can't be too hard to prescribe?

\section{References}

Dijk FN, Fitzgerald DA. The impact of newborn screening and earlier intervention on the clinical course of cystic fibrosis. Paediatr Respir Rev 2012; 13: 220-225.

2 Dijk FN, McKay K, Barzi F, et al. Improved survival in cystic fibrosis patients diagnosed by newborn screening compared to a historical cohort from the same centre. Arch Dis Child 2011; 96: 1118-1123.

3 Evans AK, Fitzgerald DA, McKay KO. The impact of meconium ileus on the clinical course of children with cystic fibrosis. Eur Respir J 2001; 18: 784-789.

4 Mott LS, Park J, Murray CP, et al. Progression of early structural lung disease in young children with cystic fibrosis assessed using CT. Thorax 2012; 67: 509-516.

Sly PD, Gangell CL, Chen L, et al. Risk factors for bronchiectasis in children with cystic fibrosis. N Engl J Med 2013; 368: 1963-1970. 
Hoo AF, Thia LP, Nguyen TT, et al. Lung function is abnormal in 3-month-old infants with cystic fibrosis diagnosed by newborn screening. Thorax 2012; 67: 874-881.

7 Rosenfeld M, Farrell PM, Kloster M, et al. Association of lung function, chest radiographs and clinical features in infants with cystic fibrosis. Eur Respir J 2013; 42: 1545-1552.

8 Tiddens HA, Stick SM, Davis S. Multi-modality monitoring of cystic fibrosis lung disease: the role of chest computed tomography. Paediatr Respir Rev 2013 [In press DOI: 10.1016/j.prrv.2013.05.003].

9 Rand S, Hill L, Prasad SA. Physiotherapy in cystic fibrosis: optimising techniques to improve outcomes. Paediatr Respir Rev 2013; 14: 263-269.

10 Warnock L, Gates A, van der Schans CP. Chest physiotherapy compared to no chest physiotherapy for cystic fibrosis. Cochrane Database Syst Rev 2013; 9: CD001401.

11 Accurso FJ, Rowe SM, Clancy JP, et al. Effect of VX-770 in persons with cystic fibrosis and the G551D-CFTR mutation. N Engl J Med 2010; 363: 1991-2003.

12 Sawicki GS, Ren CL, Konstan MW, et al. Treatment complexity in cystic fibrosis: trends over time and associations with site specific outcomes. J Cyst Fibros 2013; 12: 461-467.

13 Schneiderman JE, Wilkes DL, Atenafu EG, et al. Longitudinal relationship between physical activity and lung health in patients with cystic fibrosis. Eur Respir J 2014; 43: 817-823.

14 Hebestreit A, Kersting U, Basler B, et al. Exercise inhibits epithelial sodium channels in patients with cystic fibrosis. Am J Respir Crit Care Med 2001; 164: 443-446.

15 Kerem E, Viviani L, Zolin A, et al. Factors associated with FEV1 decline in cystic fibrosis: analysis of the ECFS patient registry. Eur Respir J 2014; 43: 125-133.

16 Nixon PA, Orenstein DM, Kelsey SF, et al. The prognostic value of exercise testing in patients with cystic fibrosis. N Engl J Med 1992; 327: 1785-1788.

17 Pianosi P, LeBlanc J, Alumudevar A. Peak oxygen uptake and mortality in children with cystic fibrosis. Thorax 2005; 60: 50-54.

18 Klijn PH, van der Net J, Kimpen JL, et al. Longitudinal determinants of peak aerobic performance in children with cystic fibrosis. Chest 2003; 124: 2215-2219.

19 Werkman MS, Hulzebos EHJ, Helders PJM, et al. Estimating peak oxygen uptake in adolescents with cystic fibrosis. Arch Dis Child 2014; 99: 21-25.

20 Teoh OH, Trachsel D, Mei-Zahav M, et al. Exercise testing in children with lung diseases. Paediatr Respir Rev 2009; 10: 99-104.

21 Selvadurai HC, Cooper PJ, Meyers N, et al. Validation of shuttle tests in children with cystic fibrosis. Pediatr Pulmonol 2003; 35: 133-138.

22 Saynor ZL, Barker AR, Oades PJ, et al. A protocol to determine valid $V^{\prime} \mathrm{O}_{2}$ max in young cystic fibrosis patients. $J$ Sci Med Sport 2013; 16: 539-544.

23 Cooper DM, Weiler-Ravell D, Whipp BJ. Aerobic parameters of body size during growth in children. J Appl Physiol Respir Environ Exerc Physiol 1984; 56: 628-634.

24 Fitzgerald NM, Fitzgerald DA, Lands L, et al. Diffusion capacity in children: what happens with exercise? Paediatr Respir Rev 2013; 14: 190-194.

25 Sheehan J, Massie J, Hay M, et al. The natural history and predictors of persistent problem behaviours in cystic fibrosis: a multicentre prospective study. Arch Dis Child 2012; 97: 625-631.

26 Eakin MN, Bilderback A, Boyle MP, et al. Longitudinal association between medication adherence and lung health in people with cystic fibrosis. J Cyst Fibros 2011; 10: 258-264.

27 Isaacs D, Fitzgerald D. Seven alternatives to evidence based medicine. BMJ 1999; 319: 1618.

28 Gaskin KJ. Nutritional care in children with cystic fibrosis: are our patients becoming better? Eur J Clin Nutr 2013; 67: 558-564.

29 Wang Y, Lobstein TM. Worldwide trends in childhood overweight and obesity. Int J Pediatr Obes 2006; 1: 11-25. 